\title{
Importance of Routine Histopathology of Gallbladder after Elective Cholecystectomy for Gallstones
}

\author{
Umair Ahmed Khan, ${ }^{1}$ Munazza Iqbal, ${ }^{2}$ Imran Aslam, ${ }^{3}$ Khalid Masood Gondal, ${ }^{4}$ Shahid Alam ${ }^{5}$
}

\begin{abstract}
Introduction: Gallstones are the hard deposits in the gallbladder, which is a sac - like organ lying on the inferior surface of liver in the right upper quadrant of abdomen. Cholecystectomy is the first line surgical procedure to manage symptomatic gallstone. Carcinoma gallbladder carries worst prognosis of all cancer mortality and seen in patients with chronic cholecystitis due to cholelithiasis. The purpose of conducting
\end{abstract}

Date of Submission 8-11-2015

Date of Revision Received 10-2-2016

Date of Acceptance for Publication 19-2-2016

Conflict of Interest: None

Funding Source: None

Khan U.A. ${ }^{1}$

Registrar, North Surgical Ward, Mayo Hospital, Lahore

Iqbal M. $^{2}$

Professor of Pathology

Fatima Jinnah Medical University, Lahore

Aslam I. ${ }^{3}$

Assistant Professor

Department of Surgery, KEMU/ Mayo Hospital, Lahore

Gondal K.M. ${ }^{4}$

Chairman

Department of Surgery, KEMU/ Mayo Hospital, Lahore

Alam S. ${ }^{5}$

Registrar, North Surgical Ward, Mayo Hospital, Lahore this study was to highlight the fact, that the histopathology of the gallbladder in Pakistan is only restricted to those specimens, which are associated with macroscopic abnormalities.

Objective: The frequency of gallbladder carcinoma in routine histopathology after elective Cholecystectomy for gallstones who did not show any macroscopic findings peroperatively.

Material and Methods: This cross sectional study of 250 patients of both gender aged between $18-60$ years was conducted in surgical OPD/North Surgical Unit of Mayo Hospital, Lahore in one year duration from 01-01-2014 to 31-12-2014. The non-probability purposive sampling technique was used in this study. Informed consent was taken from all the patients. Their demographics like name, age, gender and address were noted. Open / laparoscopic cholecystectomy was performed depending upon patient's choice. All gallbladder specimens, those with no obvious gross abnormalities were sent for histopathology (Gross findings, histopathological diagnosis). All data was recorded on a pre-designed proforma and analyzed using SPSS version 20. Mean and standard deviation were used to express the continuous variables like age, stone size and duration of disease. All qualitative variables like gender, number of stones and gallbladder carcinoma were presented in the form of frequency and percentages. Stratification was done for duration of disease, number of stone, size of stone and gender to address effect modifiers. Post-stratification chi-square test was applied keeping P-value $\leq 0.05$ as significant.

Results: In this study the mean age of the patients was $39.52 \pm 12.38$ years. Among 250 patients, 75 $(30 \%)$ were males and $175(70 \%)$ females. The mean duration of disease was $5.61 \pm 2.75$ months. Gallbladder carcinoma on routine histopathology after elective 
Cholecystectomy was observed in $18(7.2 \%)$ patients whereas $232(92.8 \%)$ patients did not have gallbladder carcinoma. All of the 18 patients who had carcinoma were females which showed a highly significant difference $(\mathrm{p}<0.05)$. Among 153 cases with $<7 \mathrm{~mm}$ stone size, carcinoma was observed in 11 patients and in 97 cases with $\geq 7 \mathrm{~mm}$ stone size, carcinoma was observed in 7 cases. Among 124 cases with $<5$ months of duration of disease, carcinoma was observed in 9 patients and in 126 cases with $\geq 5$ months of duration of disease, carcinoma was observed in 9 cases. Among 93 cases with $<2$ stones, carcinoma was observed in 7 patients and in 157 cases with $\geq 2$ stones, carcinoma was observed in 11 cases. Statistically insignificant difference was found between the duration of disease, number and size of stones and carcinoma of the patients $(\mathrm{P}>0.05)$.

Conclusion: Although the frequency of gallbladder carcinoma on histopathology is low, but not negligible, therefore histopathology of gallbladder specimen is necessary to rule out carcinoma.

Keywords: Gallbladder, Carcinoma, Cholecystectomy, Gallstones, Macroscopic.

\section{Introduction}

Gallstones are the hard deposits in the gallbladder, which is a sac - like lying organ on the inferior surface of liver in the right upper quadrant of abdomen. Gallstones are common with prevalence as high as $10 \%$ to $70 \%$ in adults of developed countries, especially in white people. ${ }^{1}$ Ethnic groups like black Americans and from East Asia have reduced frequency while rare in sub Saharan Africa. Some non modifiable risk factors for gallstones are female sex, increased age, genetics and ethnicity. Modifiable risk factors are obesity, rapid weight loss, the metabolic syndrome, certain diseases (cirrhosis and Crohn disease), gallbladder stasis (from spinal cord injury or drugs, such as somatostatin), and lifestyle. ${ }^{1}$ Gallstone disease is rare in childhood, but becomes more frequent in adults with similar risk factors, particularly obesity. ${ }^{2}$

Cholecystectomy is the first line surgical management of symptomatic gallstones. Open Cholecystectomy had been recognized over centuries to be the standard. In 1980s, open cholecystectomy with a small incision was introduced as an alternative to laparoscopic cholecystectomy. ${ }^{3}$

Carcinoma gallbladder carries worst prognosis of all cancer mortalities and is seen in patients with chro- nic cholecystitis due to cholelithiasis. ${ }^{4}$ Long standing chronic irritation of gallbladder is the pathophysiology of carcinoma gallbladder. The prevalence of carcinoma in such patients are variable ranging from 0.3 to $12 \% .^{5}$

A study on 220 patients with symptomatic gallstones reported 203 showing chronic cholecystitis, 7 mucocele, 3 empyema, 1 chronic cholecystitis associated with polyp and 6 (2.8\%) showed adenocarcinoma along with cholelithiasis. ${ }^{6}$ Another study was conducted on 500 patients with Cholecystectomy reported 460 patients of chronic cholecystitis, 33 showed acute cholecystitis, 6 gangrenous cholecystitis and only 1 reported adenocarcinoma of stage 1.7

From the above statistics it is noted that carcinoma is prevalent up to $0.3-12 \%^{5}$ in patients with gallstone. So, histopathological analysis is therefore mandatory if we consider the high prevalence of carcinoma up to $12 \%$ and it can be neglected if $0.3 \%$ prevalence is considered. Moreover, discarding gallbladder specimen if it lacks any macroscopic finding is the standard practice in most of the tertiary care hospitals of Pakistan. Histopathology of the gallbladder is only restricted to those specimens, which are associated with macroscopic abnormalities. At the same time, the practice has the real justification of reducing patient's financial burden and pathologist's workload which is in contradiction to the worldwide practice of sending the entire gallbladder specimen for histological analysis for the sole purpose of identifying discrete carcinoma in early stage. Hence this study will help us to know the importance of histopathological findings of gallbladder in patients of gallstones disease.

\section{Methodology}

This study was conducted on 250 patients in surgical OPD/North Surgical Unit of Mayo Hospital, Lahore in 1 year duration from 01-01-2014 to 31-12-2014. It was a cross sectional survey and patients selection was done on the basis non-probability purposive sampling. All patients aged between $18-60$ years of either sex undergoing elective cholecystectomy for gall stones were included in the study. Patients with evidence of carcinoma gall - bladder (on clinical ground, confirmed on ultrasonography and/or CT scan) and Gallbladder showing gross abnormalities suggestive of localized infiltrative malignancy during surgery were not included in the study.

The patients were assessed clinically and advised 
ultrasound to see the status of gallbladder (presence of stone, features of chronic cholecystitis, gross abnormalities etc). Relevant investigations like $\mathrm{CBC}$, blood sugar, urea and creatinine, electrolytes etc were done as per usual protocol. Their demographics like name, age, gender and address were noted. Open/laparoscopic cholecystectomy was performed depending upon Body Mass Index (BMI) after informed consent. All gallbladder specimens, those with no obvious gross/macroscopic abnormalities were sent for histopathology. It was based on routine examination of $\mathrm{H}$ and $\mathrm{E}$ stained slides and was noted from histopathology reports from pathology department.

All data was recorded on a pre-designed proforma and analyzed using SPSS version 20. Mean and standard deviation was used to express the continuous variables like age, stone size and duration of disease. All qualitative variables like gender, number of stones and gallbladder carcinoma was presented in the form of frequency and percentages. Stratification was done for duration of disease, number of stone, size of stone and gender to address effect modifiers. Post-stratification chi-square test was applied keeping a P-value $\leq 0.05$ as significant.

\section{Results}

A total of 250 cases were enrolled in this study. The mean age of the patients was $39.52 \pm 12.38$ years with minimum and maximum ages of 18 and 60 years respectively. Mean stone size of the patients was $6.81 \pm$ $1.88 \mathrm{~mm}$ with minimum and maximum values of $4 \&$ $10 \mathrm{~mm}$ respectively. Mean duration of disease was $5.61 \pm 2.75$ months with minimum and maximum duration of 1 and 10 months respectively (Table 1).

Frequency distribution of gender showed that there were $75(30 \%)$ male patients and $175(70 \%)$ female. Histopathology of gallbladder specimen showed carcinoma in $18(7.20 \%)$ patients and no carcinoma was present in $232(92.80 \%)$ patients. All the 18 patients were female. Statistically highly significant difference was found between the gender and carcinoma of the patients i.e. $\mathrm{p}$-value $=0.004$ (Table 2).

In this study, data was stratified for stone size and found that 153 cases had stone size less than $7 \mathrm{~mm}$ in which carcinoma was observed in 11 cases and no carcinoma in 142 cases, similarly 97 cases had stone size above $7 \mathrm{~mm}$ in which carcinoma was observed in

Table 2: Distribution of Carcinoma in both genders.

\begin{tabular}{|c|c|c|c|c|}
\hline & \multicolumn{2}{|c|}{ Carcinoma } & \multirow{2}{*}{ Total } \\
\hline & & Yes & No & \\
\hline \multirow{2}{*}{ Gender } & Female* & 18 & 157 & 175 \\
\hline & Male & 0 & 75 & 75 \\
\hline \multicolumn{2}{|c|}{ Total } & 18 & 232 & 250 \\
\hline
\end{tabular}

Chi-square value $=8.313$

$*$ p-value $=0.004$ (significant) as compared to males

Table 3: Distribution of Carcinoma according to stone size.

\begin{tabular}{|c|c|c|r|r|}
\hline \multicolumn{2}{|c|}{} & \multicolumn{2}{|c|}{ Carcinoma } & \multirow{2}{*}{ Total } \\
\cline { 3 - 5 } \multicolumn{2}{|c|}{} & Yes & No & \\
\hline \multirow{2}{*}{$\begin{array}{c}\text { Stone size } \\
(\mathrm{mm})\end{array}$} & $<7$ & 11 & 142 & 153 \\
\cline { 2 - 5 } & $\geq 7$ & 7 & 90 & 97 \\
\hline \multicolumn{2}{|c|}{ Total } & 18 & 232 & 250 \\
\hline
\end{tabular}

Chi-square value $=0.00006$

$\mathrm{p}$-value $=0.99$ (Insignificant)

Table 4: Distribution of Carcinoma according to duration of disease.

\begin{tabular}{|c|c|c|c|c|}
\hline \multicolumn{2}{|c|}{} & \multicolumn{2}{c|}{ Carcinoma } & \multirow{2}{*}{ Total } \\
\cline { 3 - 5 } \multicolumn{2}{|c|}{} & Yes & No & \\
\hline \multirow{2}{*}{$\begin{array}{c}\text { Duration of } \\
\text { disease (Months) }\end{array}$} & $<5$ & 9 & 115 & 124 \\
\cline { 2 - 4 } & $\geq 5$ & 9 & 117 & 126 \\
\hline \multicolumn{2}{|c|}{ Total } & 18 & 232 & 250 \\
\hline
\end{tabular}

Chi-square value $=0.001$

p-value $=0.97$ (Insignificant) 
7 cases and no carcinoma was present in 90 cases. Statistically in-significant difference was found between the stone size and carcinoma of the patients i.e. p-value $=0.99($ Table 3$)$.

Data stratified for duration of disease showed that among 124 cases with duration of disease less than 5 months, carcinoma was observed in 9 cases and no carcinoma in 115 cases, similarly among 126 cases with duration of disease above 5 months, carcinoma was observed in 9 cases and no carcinoma in 117 cases. Statistically insignificant difference was found between the duration of disease and carcinoma of the patients i.e. p-value $=0.97$ (Table 4).

Frequency distribution of number of stones showed that one stone was found in $48(19.20 \%)$ patients, two stone were found in 45 (19\%) patients, three stones were found in $70(28 \%)$ patients and four stones were found in 87 (34.80\%) patients (Fig. 1).

Data stratified for number of stones showed that 93 cases had number of stones less than 2 among

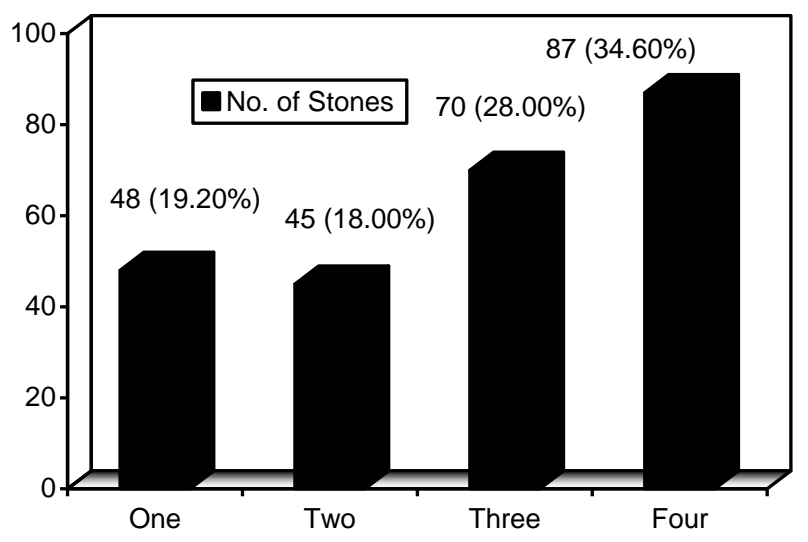

Fig. 1: Frequency distribution of number of stones.

Table 5: Distribution of Carcinoma according to number of stones.

\begin{tabular}{|l|c|c|c|c|}
\hline \multicolumn{2}{|c|}{} & \multicolumn{2}{c|}{ Carcinoma } & \multirow{2}{*}{ Total } \\
\cline { 3 - 5 } \multicolumn{2}{|c|}{} & Yes & No & \\
\hline \multirow{2}{*}{$\begin{array}{l}\text { No of } \\
\text { stones }\end{array}$} & $<2$ & 7 & 86 & 93 \\
\cline { 2 - 5 } & $\geq 2$ & 11 & 146 & 157 \\
\hline \multicolumn{2}{|c|}{ Total } & 18 & 232 & 250 \\
\hline
\end{tabular}

Chi-square value $=0.02$

$\mathrm{p}$-value $=0.87$ (Insignificant) which, carcinoma was observed in 7 cases and no carcinoma in 86 cases. Similarly 157 cases had number of stones above 2 among which, carcinoma was observed in 11 cases and no carcinoma in 146 cases. Statistically insignificant difference was found between the number of stones and carcinoma of the patients i.e. $\mathrm{p}$-value $=0.97($ Table 5)

\section{Discussion}

Cholecystectomy is one of the most commonly performed abdominal surgeries. In the U.S, annual incidence of gallbladder diseases is estimated about one million and among them approximately 500,000 - 600,000 undergo surgery. ${ }^{8}$

Gallbladder malignancy is a lethal disease and is the fifth commonest malignancy in the gastrointestinal tract. ${ }^{9}$ Clinical presentation of gallbladder malignancy and benign gallbladder disease is almost similar and most of the times it is masked by chronic cholecystitis. $^{10}$

Although carcinoma gallbladder is relatively rare in the West, but high incidence has been noted in Southwestern American Indians, Chile, Mexico, Bolivia, Poland, and Israel. ${ }^{11}$

In our study the carcinoma was observed in $7.20 \%$ patients and no carcinoma was present in $92.80 \%$ patients. Some studies are in line with our study results whereas some are in contrast.

Faisal $\mathrm{G}$ Siddiqui et al, ${ }^{6}$ demonstrated 6 cases $(2.7 \%)$ in their study to have incidental carcinoma of gallbladder. No gross abnormality was found in these gallbladder per-operatively. This incidence is low as compared to our study.

Some other studies were also conducted which showed the gallbladder carcinoma percentages in accordance with our study. These studies show an incidence varying from 6.9 to 12 percent. $^{12-14}$

Samad reported $1.1 \%$ incidence of malignancy in a patient who underwent cholecystectomy for chronic cholecystitis due to cholelithiasis. ${ }^{15}$ Among the myriad of premalignant conditions, gallstone is supposed to have the strong association with carcinoma gallbladder. $^{13}$

One study showed that Preoperative diagnosis of carcinoma of gallbladder is the exception rather than the rule, occurring in fewer than $20.0 \%$ of patients. ${ }^{16}$ Different international studies ${ }^{10,17,18}$ have reported different incidences ranging from $0.17 \%$ to $12.4 \%$.

Pradhan et al, ${ }^{19}$ showed incidence rate of $2.6 \%$ for 
primary gallbladder malignancy in Nepal.

In our study the mean age of the patients was $39.52 \pm 12.38$ years, female patients were in larger number than male. Some of the studies like Siddiqui et al showed male to female ratio of $1: 7 .^{6}$ also other studies showed Female predominance. ${ }^{20,21}$ The mean age was $32.25 \pm 5.3$ years ranging from 19 to 80 years, slightly higher than that reported in other studies. ${ }^{22}$

Amjad Abassi, et al showed that there were 25 (25\%) male and $75(75 \%)$ female patients. The age of the patients ranged from 25 to 80 years. Overall mean age was 47.71 years and Standard Deviation was 9.91. ${ }^{23}$ Highest gall bladder cancer incidence rates have been reported in women from India, Chile and Pakistan. $^{24}$

Yi-lei Deng et al, described that Out of 14,369 (60\% female and $40 \%$ male) patients undergoing cholecystectomy, Gallbladder carcinoma was found in only 46 cases $(0.32 \%) .^{25}$

\section{Conclusion}

Thus the local estimate of gallbladder carcinoma in gallstone patients without macroscopic abnormalities peroperatively is highly significant, so histopathological analysis of gallbladder specimen for the sole purpose of identifying discrete carcinoma in early stage is highly recommended. The practice will help to manage the patients on early basis and prevent their morbidity and mortality.

\section{References}

1. Stinton LM, Myers RP, Shaffer EA. Epidemiology of gallstones. Gastroenterol Clin North Am. 2010; 39 (2): 157-69.

2. Stinton LM, Shaffer EA. Epidemiology of gallbladder disease: cholelithiasis and cancer. Gut and liver, 2012; 6 (2): 172-87.

3. Mehrvarz S, Mohebi HA, Kalantar Motamedi M. Laparoscopic cholecystectomy versus small incision cholecystectomy in symptomatic gallstones disease. J Coll Physicians Surg Pak. 2012; 22 (10): 627-31.

4. Siddique K, Ali Q, Mirza S, Jamil A, Ehsan A, Latif S, et al. Evaluation of the aetiological spectrum of obstructive jaundice. J Ayub Med Coll Abbottabad, 2008; 20 (4): 62-6.

5. Inui K, Yoshino J, Miyoshi H. Diagnosis of gallbladder tumors. Inter Med. 2010; 50 (11): 1133-6.

6. Siddiqui FG, Memon AA, Abro AH, Sasoli NA, Ahmad L. Routine histopathology of gallbladder after elective cholecystectomy for gallstones: waste of resources or a justified act? BMC Surg. 2013; 13 (1): 26.

7. Khan JS, Ali H, Hassan I, Khan MM, Iqbal M. Frequency of Incidental Carcinoma Gall Bladder in Laparoscopic Cholecystectomy. J Rawal Med Coll. 2013; 17 (1): 36-8..

8. Murshid KR. Asymptomatic gallstones: Should we operate? Saudi J Gastroenterol. 2007; 13 (2): 57.

9. Scott HS. The gallbladder and extrahepatic biliary tree. In: Stacey EM, Darryl C, Joel KG, Harold AB, Victor ER, Mark HS. Sternberg's Diagnostic surgical pathology. 4th ed. Philadelphia: Lippincott Williams \& Wilkins, 2004: p. 1783.

10. Chen LF, Hsiao CH, Tsai CF. Three - stage - DEA model selections and managerial decision. African $\mathrm{J}$ Bus Manage, 2010; 4 (14): 3046-55.

11. Nakayama F. Recent progress in the diagnosis and treatment of carcinoma of the gallbladder-introduction. World J Surg. 1991; 15 (3): 313-4.

12. Siddiqui F, Soraya N. An audit of cholecystectomy specimens. J Surg Pak. 2002; 7 (2): 18-21.

13. Ayyaz M, Waris M, Fahim F. Presentation and etiological factors of cancer gall bladder in patients undergoing cholecystectomies at Mayo Hospital, Lahore. Ann King Edward Med Coll. 2001; 7: 138-40.

14. Nawaz T, Khan R, Malik A, Anwar I, Younus M. Incidence of carcinoma gall bladder in cholelithiasis. Pak $\mathbf{J}$ Surg. 2000; 16 (3): 33-6.

15. Samad A. Gall bladder carcinoma in patients undergoing cholecystectomy for cholelithiasis. J Pak Med Assoc. 2005; 55 (11): 497.

16. Manno CS, Pierce GF, Arruda VR, Glader B, Ragni M, Rasko JJ et al. Successful transduction of liver in hemophilia by AAV - Factor IX and limitations imposed by the host immune response. Nature Med. 2006; 12 (3): 342-7.

17. Bazoua G, Hamza N, Lazim T. Do we need histology for a normal - looking gallbladder? J hepato-biliary pancreat Surg. 2007; 14 (6): 564-8.

18. Hsieh J, Tsao W, Tang H, Hsu C, Wu K. Primary carcinoma of the gallbladder: a review of 10 years of experience at Tri-Service General Hospital. Zhonghua yi xue za zhi. Chinese Med J; Free China ed. 1993; 51 (3): 193-9.

19. Pradhan SB, Dali S. Relation between gallbladder neoplasm and Helicobacter hepaticus infection. Kathmandu Univ Med J. 2004; 2 (4): 331-5.

20. Channa NA, Soomro AM, Ghangro AB. Cholecystectomy is becoming an increasingly common operation in Hyderabad and adjoining areas. Rawal Med J. 2007; 32 (2): 128-30.

21. Murshid K. Symptomatic gallstones: a disease of young Saudi women. Saudi J Gastroenterol. 1998; 4 (3): 159.

22. Ali SA, Tahir SM, Soomoro AG, Siddiqui AJ, Memon AS. Open cholecystectomy without intraperitoneal drainage. J Ayub Med Coll Abbottabad, 2010; 22 (2): 29- 
31.

23. Abassi A, Qasmi SA, Ghafoor A, Kiani F, Abassi H. Frequency of carcinoma gallbladder in cases of cholelithiasis undergoing cholecystectomy at tertiary care hospital. Rawal Med J. 2012; 37 (4): 406-8.

24. Genç V, Onur Kirimker E, Akyol C, Kocaay AF, Karabörk A, Tüzüner A et al. Incidental gall bladder cancer diagnosed during or after laproscopic cholecystectomy in members of the Turkish population with gall stone disease. Turk J Gastroenterol. 2011; 22: 513-6.

25. Deng Y-1, Xiong X-z, Zhou Y, Shrestha A, Li F-y, Cheng N-s. Selective histology of cholecystectomy specimens-is it justified? J Surgl Res. 2015; 193 (1): 196201. 